\title{
Studi Kondisi Eksisting Sistem Pengelolaan Air Limbah Domestik Setempat di Kota Denpasar
}

\author{
Muhammad Sonny Abfertiawan ${ }^{1}$, Pham Ngoc Bao², Widia Rahmawati Pahilda ${ }^{3}$, dan \\ Muhammad Fahmi Hakim ${ }^{3}$
}

${ }^{1}$ Kelompok Keahlian Rekayasa Air dan Limbah Cair, Fakultas Teknik Sipil dan Lingkungan, Institut Teknologi Bandung; e-mail: msa@ftsl.itb.ac.id

2Institute for Global Environmental Strategies, Japan;

${ }^{3}$ Ganeca Environmental Services, Bandung;

\begin{abstract}
ABSTRAK
Pengelolaan air limbah domestik (ALD) di Indonesia masih dihadapkan dengan cukup banyak tantangan teknis maupun nonteknis. Beberapa data menunjukkan masih terdapat 10,41\% penduduk Indonesia yang memiliki perilaku buang air besar sembarangan (BABS) dan 32,1\% penduduk belum memiliki pengelolaan sanitasi yang layak. Sebagai negara yang memiliki populasi 260 juta jiwa, terbesar keempat di dunia, dan luas mencapai 2 juta $\mathrm{km}^{2}$,Indonesia terus berupaya untuk meningkatkan akses masyarakat terhadap pengelolaan ALD yang efektif dan efisienuntuk mencapai pembangunan berkelanjutan.Denpasar, kota pariwisata di Indonesia, memiliki kepentingan terhadap upaya peningkatan pengelolaan air limbah domestik agar tidak memberikan dampak terhadap industri pariwisata. Hasil studi menujukkan bahwa pengelolaan ALD di Denpasar masih didominasi dengan sistem setempat yakni sebesar 96,8\% dari total populasi.Sebesar 3\% populasi telah dilayani oleh jaringan perpipaan terpusat dan $0,2 \%$ populasi masih memiliki perilaku BABS.Sistem setempat dipandang masih menjadi solusi terbaik dalam pengelolaan ALD di Indonesia. Namun, sistem ini dinilai memiliki banyak tantanganterkait dengan institusi pengelolaan, finansial, infrastruktur pengolahan setempat, dan regulasi. Oleh karena itu, Kota Denpasar memiliki tantangan yang besar untuk memastikan sistem pengelolaan ALD dapat berjalan dengan baik. Makalah ini mendeskripsikan kondisi eksisting sistem pengelolaan ALD setempat diDenpasar yang meliputi sub-sistem pengolahan setempat, sub-sistem pengangkutan, dan subsistem pengolahan lumpur tinja.Metode penelitian yang digunakan meliputi kajian data sekunder dan primer secara kualititatif serta kuantitatif diantaranya kuisioner, wawancara, diskusi kelompok terarah, dan analisis laboratorium. Penelitian ini menjadi dasar dalam pengembangan model pengelolaan air limbah domestik setempat di Kota Denpasar.
\end{abstract}

Kata kunci: air limbah domestik, sanitasi, lumpur tinja, denpasar

\begin{abstract}
Management of domestic wastewater in Indonesia is still faced with quite a number of technical and non-technical challenges. Some data show that there are still $10.41 \%$ of the Indonesian population who have open defecation (OD) behavior and 32,1\% of population do not served by a proper sanitation system. As a country that has a population of 260 million, the fourth largest in the world, and 2 million $\mathrm{km}^{2}$ of area, Indonesia continues to increase people's access to the effective and efficient domestic wastewater systemin order to achieve sustainable development. Denpasar, as one of the major tourism cities in Indonesia, has an interest in efforts to improve domestic wastewater management so as not to have a negative impact on the tourism industry. The results of the study show that the management of domestic wastewater in Denpasar is still dominated by the on-site system, 96.8\% of the population. $3 \%$ of the population has been served by a off-site system and $0.2 \%$ of the population still has OD behavior. The on-site system is seen as still the best solution in managing domestic wastewater in Indonesian. However, this system is considered to still have quite a number of problems related to management institutions, finance, on-site treatment infrastructure, and regulations. Therefore, the city of Denpasar has a big challenge to ensure that the domestic wastewater management system can run well. This paper describes the existing conditions of on-site domestic wastewater systems in Denpasar City which include on-site sub-systems, septage transportation sub-systems, and septage sludge treatment sub-systems. The research methods used included the study of secondary and primary data qualitatively and quantitatively including questionnaires, interviews, focus group discussions, and laboratory analysis. This research was conducted to become the basis for developing a buisness model of septage management in Denpasar City.
\end{abstract}

Keywords: Wastewater, Sanitation, Septage, Denpasar

Citation: Abfertiawan, M. S., Bao, P. N., Pahilda, W. R., dan Hakim, M. F. (2019). Studi Kondisi Eksisting Sistem Pengelolaan Air Limbah Domestik Setempat di Kota Denpasar. Jurnal Ilmu Lingkungan, 17(3), 443-451, doi:10.14710/jil.17.3.443-451 


\section{Pendahuluan}

Indonesia merupakan salah satu negara berkembang di Asia Tenggara (ASEAN)yang memiliki populasi mencapai 260 juta jiwa pada tahun 2017 (Badan Pusat Statistik RI, 2018). Word Bank (2016) memprediksi populasi Indonesia akan berpotensi melebihi 290 juta jiwa pada tahun 2045. Besarnya populasi Indonesia saat ini maupun di masa yang akan datang menimbulkan tantangan yang besar terhadap pemenuhan kebutuhan infrastruktur pendukung khususnya terkait dengan air dan sanitasi di perkotaan. Tantangan ini semakin besar jika merujuk pada data bahwa $67,5 \%$ penduduk Indonesia akan tinggal di daerah perkotaan pada tahun 2025 (Word Bank, 2016).

Sanitasi merupakan salah satu permasalahan lingkungan yang masih dihadapi oleh banyak kota di Indonesia. Secara umum, akses sanitasi di Indonesia telah meningkat secara signifikan dari $45 \%$ pada tahun 1990 menjadi 85\% pada tahun 2016 (JMP, 2017). Menurut Kementerian Perencanaan Pembangunan Nasional (Bappenas), Pemerintah Indonesia telah berhasil menurunkan persentase perilaku Buang Air Besar Sembarangan (BABS) sebesar 1,4\% per tahun, dari $24,8 \%$ pada tahun 2007 hingga mencapai 10,41\% pada tahun 2017. Selain itu, akses terhadap sanitasi meningkat rata-rata $2 \%$ per tahun, dari $58,77 \%$ pada tahun 2007 hingga mencapai 76,92\% pada tahun 2018. Data yang relatif sama dipublikasikan oleh ASEAN Secretariat/ASEANstats database yang menyebutkan pada tahun 2017 terdapat 67,9\% populasi Indonesia sudah mendapatkan akses terhadap sanitasi yang layak atau improved sanitation (ASEAN Key Figures, 2018). Namun, persentase ini masih menempati Indonesia di posisi ke-10 dari negara-negara anggota ASEAN. Data-data tersebut memperlihatkan bahwa pengelolaan sanitasi di Indonesia masih dihadapi cukup banyak tantangan.

Pengelolaan sanitasi, khususnya air limbah domestik sangat penting untuk dilakukan secara efektif dan efisien. Air limbah domestik yang tidak diolah dengan baik berpotensi mencemari lingkungan dan menimbulkan dampak negatif terhadap kesehatan manusia (SNV, 2017). Bank Dunia memperkirakan bahwa sanitasi yang buruk telah menyebabkan lebih dari 120 juta penyakit dan 50.000 kematian setiap tahun (World Bank, 2008). Indonesia diperkirakan dapat mengalami kerugian sebesar Rp56 triliun atau $\$ 4,2$ miliar per tahun karena buruknya kualitas sanitasi (World Bank, 2017).

Dalam Rencana Pembangunan Jangka Menengah Nasional (RPJMN) 2015-2019, Pemerintah Indonesia menargetkan untuk dapat memenuhi $100 \%$ akses sanitasi masyarakat pada tahun 2019. Program ini memprioritaskan pada pengembangan Sistem Pengelolaan Air Limbah Domestik Setempat (SPALDS), yakni sebesar $85 \%$ dari total target yang akan dicapai sedangkan $15 \%$ akan dikembangkan metode SPALD Terpusat (SPALD-T). Dalam perspektif teknis dan non-teknis, pengembangan SPALD Setempat di Indonesia cenderung memiliki tantangan yang lebih besar. Kesuksesan pengembangan SPALD Setempat akan sangat bergantung pada kondisi infrastruktur pengolahan setempat masyarakat, metode penyedotan dan pengangkutan lumpur tinja, institusi yang terlibat, konsep finansial dan penagihan, serta sistem pengolahan lumpur tinja yang digunakan. Hasil studi yang dilakukan oleh Water.org diketahui bahwa terdapat 51 juta masyarakat Indonesia yang masih belum memiliki sistem pengolahan air limbah domestik yang efektif. Dalam 20 tahun terakhir, lebih dari 150 Instalasi Pengolahan Lumpur Tinja (IPLT) telah dibangun di kota-kota besar, tetapi kurang dari $10 \%$ dioperasikan dengan baik (Indiyani et al., 2017). Hal ini menunjukkan bahwa pengembangan SPALD Setempat di Indonesia masih memerlukan strategi yang tepat sehingga dapat dilaksanakan dengan efektif dan efisien.

Penelitian ini merupakan hasil studi komprehensif terhadap pengelolaan lumpur tinja di kota besar Indonesia dengan mengambil studi kasus Kota Denpasar, Bali. Studi pengelolaan lumpur tinja dilakukan terhadap aspek teknis dan non teknis yang meliputi Sub-sistem Pengolahan Setempat, Subsistem Pengangkutan, dan Sub-sistem Pengolahan Lumpur Tinja. Makalah ini fokus dalam penjabaran kondisi eksisting pengelolaan lumpur tinja di Kota Denpasar, Bali. Hasil penelitian diharapkan dapat menjadi masukan dalam pengembangan model pengelolaan lumpur tinja di kota besar Indonesia, khususnya Kota Denpasar.

\section{Bahan dan Metodologi \\ 2.1. Profil Kota Denpasar}

Denpasar adalahIbu Kota Provinsi Bali yang terletak di bagian selatan Pulau Bali.Kota ini merupakan salah satu daerah pariwisata populer di Indonesia yang menjadi destinasi bagi turis dalam negeri maupun manca negara. Tanpa menghitung turis, menurut Badan Pusat Statistik (2016), Denpasar memiliki populasi sebesar 897.300 jiwa dengan luas $12.778 \mathrm{Ha}$ atau 2,27\% dari total luas Provinsi Bali. Dengan elevasi antara 12-75 meter diatas permukaan laut (mdpl), 2.444 hektar dari total area Denpasarmerupakan areapersawahan, 510 Ha lahan pertanian bukan sawah, dan sisanya seluas $9.824 \mathrm{Ha}$ sebagai lahan untuk jalan, pemukiman, kantor, sungai, dan lain-lain (Kota Denpasar dalam Angka, 2017).

Pengelolaan air limbah domestik Kota Denpasar dikelola oleh Unit Pelaksana Teknis Pengelolaan Air Limbah (UPT PAL) dan saat ini telah menjadi Badan Layanan Umum Daerah (BLUD) dibawah pemerintah Provinsi Bali. Sejak tahun 2007, Denpasar telah membangun dan mengoperasikan SPALDTerpusat melalui jaringan perpipaan untuk mengalirkan air limbah domestik menuju ke Instalasi Pengolahan Air Limbah Domestik (IPALD) yang berlokasi di Suwung. IPALD ini dibangun dengan kapasitas $51.000 \mathrm{~m}^{3} /$ hari untuk melayani masyarakat di Denpasar, Sanur dan Kuta. Sistem tersebut diperkirakan akan melayani $30 \%$ dari total populasi Kota Denpasar. Selain IPALDSuwung, Denpasar juga telah memiliki Instalasi 
Pengolahan Lumpur Tinja (IPLT) yang berlokasi sama dengan IPALD Suwung. IPLT yang dibangun pada tahun 2016 ini telah beroperasi untuk melayani masyarakat Kota Denpasar dengan kapasitas 400 $\mathrm{m}^{3} /$ hari.

\subsection{Pengumpulan Data}

Studi ini dilakukan pada tahun 2016 sampai 2017 di Kota Denpasar untuk menginvestigasi kondisi eksisting SPALD-S di Kota Denpasar meliputi pengolahan setempat masyarakat, pengangkutan lumpur tinja, dan pengolahan lumpur tinjadi IPLT Suwung.Studi dilakukan dengan mengumpulkan data primer dan sekunder terkait pengelolaan lumpur tinja, yaitu sebagai berikut:

a. Data Primer: Dilakukan dengan menggunakan metode kuantitatif dan kualitatif. Data Kuantitatif dikumpulkan dengan cara: (1) Wawancara menggunakan kuesioner yang disebarkan kepada 100 responden di Kota Denpasar, total 200 responden selama 2 tahun penelitian; (2) In-depth interview, dilakukan dengan melakukan wawancara berdasarkan pedoman wawancara sebagai acuan pertanyaan yang ditunjukkan untuk NGO'S, pemerintah daerah, perusahaan layanan sedot tinja); (3) Focus Grup Discussion, hal ini dilakukan untuk mengumpulkan opini dan penyelesaian solusi permasalahan pengelolaan lumpur tinja di Kota Denpasar, (4) pengambilan sampel dan analisis laboratorium sampel lumpur tinja, lihat Gambar 1;

b. Data sekunder yang dikumpulkan meliputi: (1) kumpulan peraturan, perundang-undangan dan kebijakan, pengaturan kelembagaan, dan standar operasional dalam layanan pengelolaan lumpur tinja di kota studi kasus; (2) informasi mengenai Kota Denpasar seperti jumlah penduduk, laju pertumbuhan penduduk, topografi, iklim, karakteristik fisik dan geografis, batas-batas kota dan peta area penting dalam konteks pengelolaan lumpur tinja, tantangan dan peluang potensial untuk layanan pengelolaan lumpur tinja, dan kualitas penyedia layanan; (3) teknologi dan sistem sanitasi di SPALD-T dan SPALD-S yang saat ini digunakan, timbulan lumpur tinja dari SPALD-
S; dan (4) metode pengosongan atau penyedotan di pengolahan setempat masyarakat

\section{Hasil dan Diskusi \\ 3.1. Septage Flow Diagram (SFD)}

SFD dikembangkan untuk menggambarkan kondisi pengelolaan air limbah domestik di Kota Denpasar. SFD diperoleh dan dianalisis berdasarkan data dari pemerintah lokal dan survei langsung terhadap kondisi eksisting pengelolaan lumpur tinja di Kota Denpasar. Hasil analisisSFD Kota Denpasar dapat dilihat pada Gambar 2.

Berdasarkan data yang diperoleh dari UPT PAL Provinsi untuk SPALD-T, diketahui bahwajumlah sambungan rumah dalam programDenpasar Sewerage Development Program(DSDP) pada tahun 2016 telah mencapai 8.500 sambungan rumah (SR) atau setara 3\% dari populasi di Kota Denpasar. Jika dihitung terhadap volume lumpur tinja, maka angka ini dapat disetarakan dengan 1.099,85 m³/tahun lumpur tinja yang telah dialirkan melalui jaringan perpipaan kota dan diolah secara efektif di IPAL Suwung sebelum dibuang ke badan air penerima.

Pengelolaan air limbah domestik di Kota Denpasar masih didominasi oleh sistem setempat atau SPALD-S. Hal ini diketahui berdasarkan analisis data survey kuisioner. Terdapat $96,8 \%$ dari total populasi masih menggunakan pengolahan setempat untuk mengolah air limbah domestik. Secara umum, lumpur tinja yang mengendap di pengolahan setempat masyarakat di Kota Denpasar disedot dan diangkut meggunakan truk tangki lumpur tinja secara legal menuju ke IPLT Suwung. Namun, lumpur tinja belum dapat diolah secara optimal di IPLT Suwung. Hal ini dikarenakan masih terdapat permasalahan operasional di IPLT Suwung yang mengakibatkan lumpur tinja tidak dapat diolah secara efektif dan efisien. Hasil analisis laboratorium terhadap efluen IPLT Suwung menunjukkan konsentrasi BOD yang masih diatas baku mutu linkungan yakni $805 \mathrm{mg} / \mathrm{L}$ dan $1.226 \mathrm{mg} / \mathrm{L}$ (lihat Tabel 1). Pengelola IPLT Suwung bersama Pemerintah Pusat masih terus berupaya meningkatkan performa IPLT Suwung agar dapat mengolah lumpur tinja secara efektif dan memenuhi baku mutu lingkungan yang berlaku.

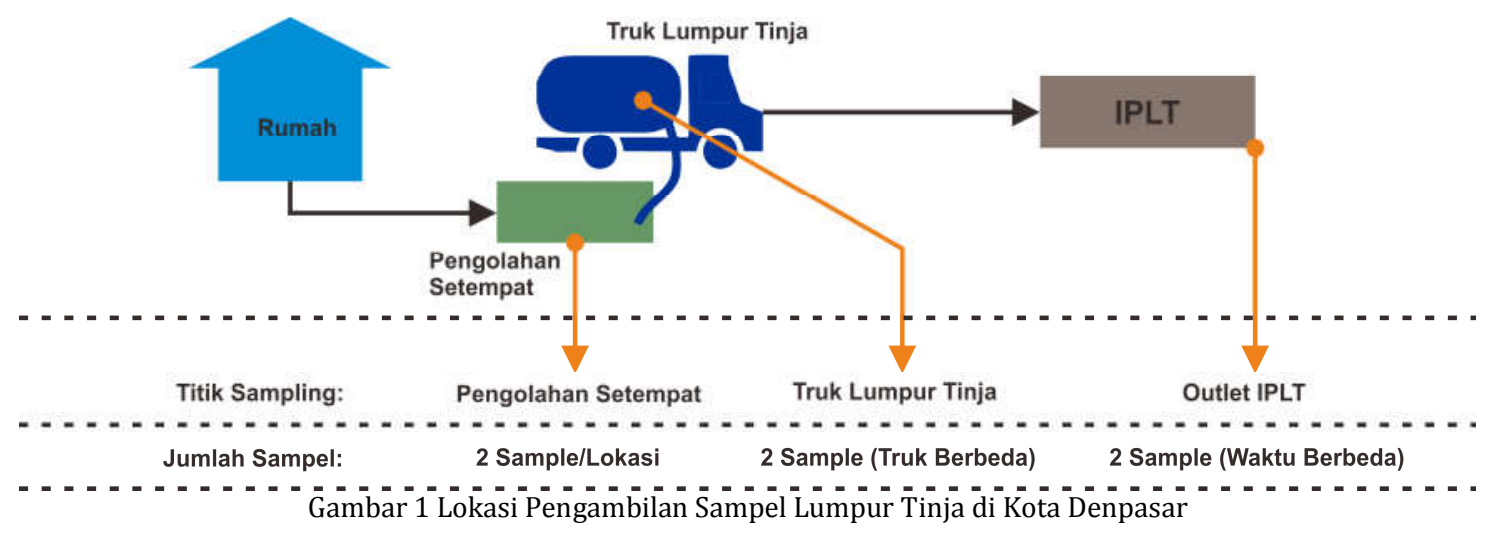


Selanjutnya, data dari Sanitasi Total Berbasis Masyarakat (STBM)yang dikelola oleh Kementerian Kesehatan Republik Indonesiapada tahun 2017 menunjukkan bahwa terdapat $0,2 \%$ populasi Kota Denpasar masih memiliki perilaku Buang Air Besar Sembarangan (BABS)atau Open Defecation (OD). Hasil pengamatan menunjukkan bahwa perilaku BABS di Kota Denpasar didominasi oleh masyarakat yang tinggal di permukiman padat dan berlokasi di bantaran sungai. Masyarakat tersebut membuang air limbah domestiksecara langsung ke badan air penerima tanpa melalui sistem pengolahan setempat yang layak.

Analisis SFD ini menunjukkan bahwa pengelola air limbah domestik di Kota Denpasar harus difokuskan pada sistem setempat. Hal ini untuk memastikan sistem setempat tidak memberikan dampak terhadap lingkungan di Kota Denpasar.

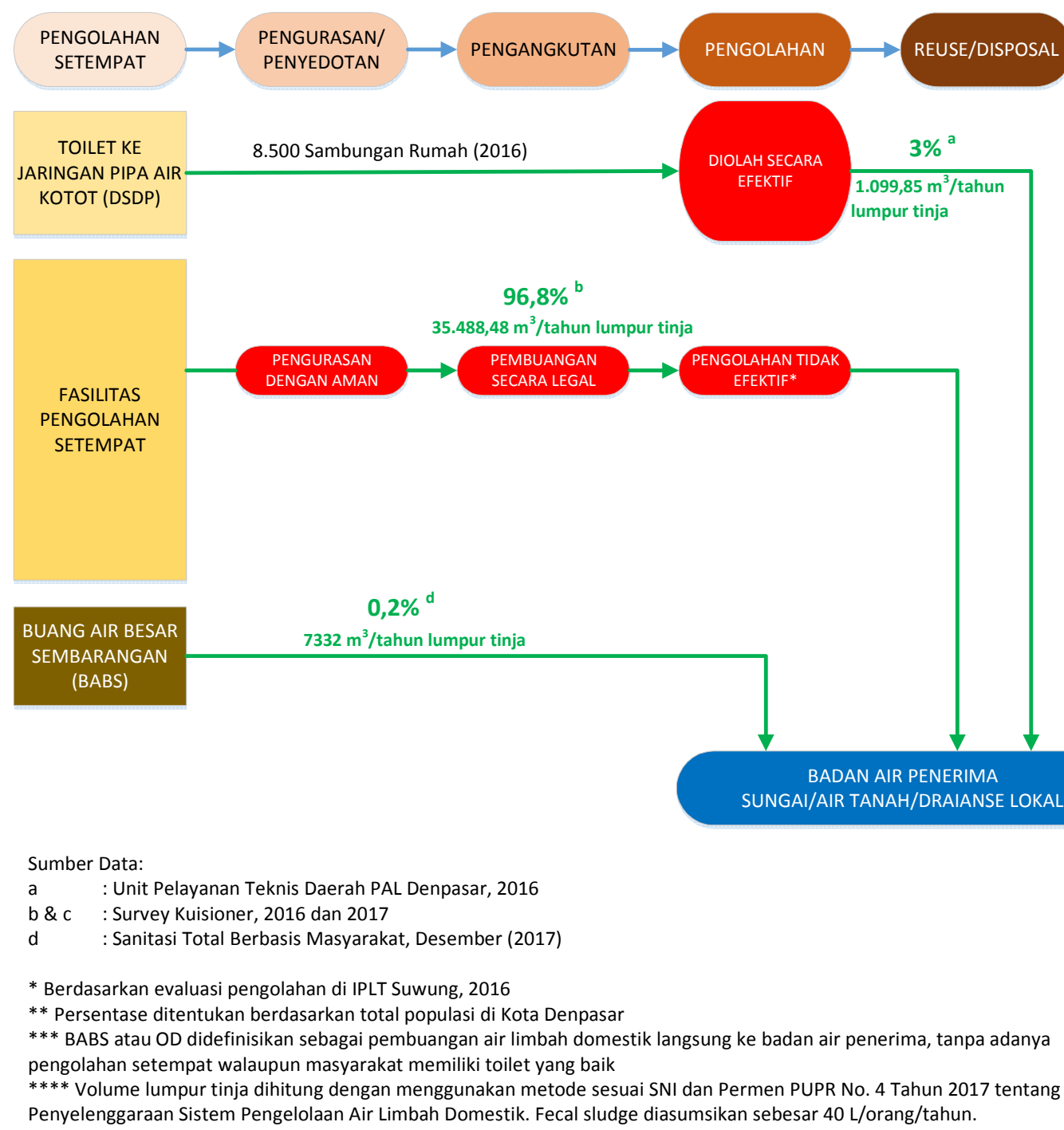

\section{Gambar 2 Septage Flow Diagram (SFD) Kota Denpasar}

\subsection{Karakteristik Lumpur Tinja}

Pengambilan sampel dan analisis laboratorium terhadap sampel lumpur tinja telah dilakukan. Sampel lumpur tinja di Kota Denpasar diambil dari pengolahan setempat berupa tangki septik, truk lumpur tinja, dan efluen di outletIPLT Suwung. Di pengolahan setempat,pengambilan sampel dilakukan terhadap tangki septik yang belum dikosongkan selama 2 tahun (DPS-ST-1) dan 8 tahun (DPS-ST-2).

Hasil analisa laboratorimum lumpur tinja dapat dilihat pada Tabel 1. Sampel lumpur tinja dari tangki septik memiliki konsentrasi Biological Oxygen Demand(BOD) dengan rentang nilai 14.489 hingga 446
$49.337 \mathrm{mg} / \mathrm{L}$. Sedangkan, nilai COD berada pada rentang 17.715 hingga $93.300 \mathrm{mg} / \mathrm{L}$. Nilai BOD dan COD yang cukup fluktuatiftersebut dipengaruhi oleh beberapa faktor, salah satunya yakniperiode penyedotan tangki septik. Rasio COD/BOD diketahui berada pada rentang 1,85 - 2,27. Nilai rasio ini menunjukkan bahwa lumpur tinja didominasi oleh material organik yang dapat didegradasi secara biologi. Untuk tangki septik, lumpur tinja dapat memiliki rasio COD/BOD 1,43-3,00, dapat dikategorikan sebagai biodegradable (Henze et al., 2008). 
Lumpur tinja di setiap kota di Indonesia dapat memiliki karakteristik yang berbeda-beda. Hal ini dapat disebabkankarena beberapa faktor,yakni: (1) kualitas unit pengolahan setempat; (2) budaya dan perilaku masyarakat dalam pengelolaan lumpur tinja; (3) penggunaan jumlah air bersih. Selain itu, perbedaan karakteristik lumpur tinja juga dapat disebabkan karena perbedaankebiasaan masyarakat dan karakteristik masyarakat yang unik,perbedaan ukuran tangki septik, dll. (USEPA 2002; Lossing et al. 2010). Sebagai contoh, di Aceh Utara, lumpur tinja memiliki nilai BOD antara 1.900 dan $2.500 \mathrm{mg} / \mathrm{L}$. Menurut USEPA, di Amerika Serikat nilai BOD dapat mencapai maksimum $78.600 \mathrm{mg} / \mathrm{L}$ sedangkan di Eropa dan Kanada dapat mencapai $25.000 \mathrm{mg} / \mathrm{L}$
(USEPA, 1984). Namun, USEPA merekomendasikan bahwa nilai rata-rata BOD yang dapat digunakan dalam perancangan IPLTyakni $7.000 \mathrm{mg} / \mathrm{L}$. Pada tahun 2005, BORDA juga melakukan penelitian untuk memahami karakteristik lumpur tinja di Bangalore, India. Studi tersebut menunjukkan bahwa konsentrasi BOD dapat mencapai $21.250 \mathrm{mg} / \mathrm{L}$.

Karakteristik lumpur tinja penting untuk diidentifikasi secara hati-hati karena setiap kota berpotensi memiliki karakteristikyang berbeda-beda. Dari perspektif desain,datakarakteristik lumpur tinja diperlukanuntuk mendapatkan data dasar dalam merancang setiap unit pengolahan lumpur tinja. Dtaa tersebut juga penting dalam kegiatan pengoperasian dan perawatan instalasi pengolahan.

Tabel 1. Hasil karakterisasi lumpur tinja di Kota Denpasar

\begin{tabular}{|c|c|c|c|c|c|c|c|c|}
\hline \multirow{2}{*}{ No } & \multirow{2}{*}{ Parameter } & \multirow[b]{2}{*}{ Unit } & \multicolumn{6}{|c|}{ Hasil Analisis Laboratorium } \\
\hline & & & DPS-ST-1 & DPS-ST-2 & DPS-T-1 & DPS-T-2 & DPS-0-1 & DPS-0-2 \\
\hline 1. & TSS & $\mathrm{mg} / \mathrm{L}$ & 85.230 & 31.600 & 60.310 & 5.086 & 9.492 & 10.760 \\
\hline 2. & TS & $\mathrm{mg} / \mathrm{L}$ & 181.617 & 18.457 & 31.658 & 7.114 & 5.394 & 3.418 \\
\hline 3. & VSS & $\mathrm{mg} / \mathrm{L}$ & 74.480 & 28.130 & 56.090 & 4.384 & 8.288 & 10.042 \\
\hline 4. & Ammonia & $\mathrm{mg} / \mathrm{L}$ & 268 & 59,9 & 23,9 & 56,4 & 25,2 & 13,4 \\
\hline 5. & Ammonia Bebas & $\mathrm{mg} / \mathrm{L}$ & 85.7 & 457 & 165 & 7 & 63 & 17,9 \\
\hline 6. & Total N & $\mathrm{mg} / \mathrm{L}$ & 2.142 & 1.496 & 599 & 1.260 & 315 & 173 \\
\hline 7. & Total P & $\mathrm{mg} / \mathrm{L}$ & 31,5 & 89,4 & 5,89 & 29,3 & 35,4 & 4,57 \\
\hline 8. & BOD & $\mathrm{mg} / \mathrm{L}$ & 49.337 & 14.489 & 22.840 & 8.680 & 856 & 1.226 \\
\hline 9. & COD & $\mathrm{mg} / \mathrm{L}$ & 93.300 & 32.842 & 42,296 & 17.715 & 5.474 & 2.787 \\
\hline 10. & Coliform & $\mathrm{MPN} / 100 \mathrm{~mL}$ & $7,5 \times 10^{4}$ & $2,1 \times 10^{6}$ & $2,4 \times 10^{5}$ & $2,4 \times 10^{5}$ & $4,6 \times 10^{6}$ & $2,4 \times 10^{5}$ \\
\hline
\end{tabular}

Keterangan: DPS: Denpasar; T: Truk Tinja; ST: TangkiSeptik; O: Outlet IPLT;

\subsection{Sub-sistem Pengolahan Setempat}

Survey kuisioner dilakukan untuk mengetahui karakteristik bangunan pengolahan setempat masyarakat di Kota Denpasar. Hasil survey menunjukkan bahwa hanya $30 \%$ responden yang memiliki konstruksi pengolahan setempat yang kedap air. Hal ini dapat diartikan bahwa pengolahan setempat tersebut merupakan tangki septik yang telah sesuai dengan Standar Nasional Indonesia (SNI) 2398:2017. Terdapat 70\% masyarakat yang tidak melapisi pengolahan setempatnya secara kedap, tidak sesuai dengan SNI. Hal ini dikarenakan ketidaktahuan masyarakat tentang standar kedap untuk tangki septik. Pengolahan setempat tersebut hanya dibangun dari material pasangan bata yang tidak kedap. Teknologi ini dikenal dengan sebutan cubluk, bukan tangki septik, yang dirancang untuk meresapkan air limbah kedalam tanah secara natural. Tentu, penggunaan cubluk berpotensi menyebabkanlumpur tinja dapat meresap ke dalam tanah dan mencemari air tanah, khususnya air tanah dangkal. Situasi ini juga ditemukan di kota-kota lain di seluruh Indonesia karena terbatasnya pengetahuan tentang standar tangki septik.Menurut Soesanto (2000), masalah yang paling umum dalam pembangunan tangki septik adalah: (1) tangki septik tidak dibangun dengan benar, sehingga ada kebocoran; (2) ukuran tangki septik tidak sesuai dengan kebutuhan rumah tangga; (3) aliran efluen terletak terlalu dekat dengan aliran influen; dan( 4) Tidak ada pipa ventilasi dan lubang akses untuk mengosongkan tangki septik.
Kondisi pengolahan setempat yang tidak kedap ini juga dapat dilihat dari persentase masyarakat yang melakukan penyedotan secara rutin. Hasil survey menunjukkan $60 \%$ responden tidak pernah melakukan pengurasan atau penyedotan dalam periode 5 tahun. Perilaku ini dapat menjadi indikator bahwa pengolahan setempat dibangun dari material yang tidak kedap sehingga tangki septik cenderung tidak pernah penuh. Sesuai dengan Peraturan Menteri Pekerjaan Umum dan Perumahan Rakyat No. 4 Tahun 2017 tentang Penyelenggaraan Sistem Pengelolaan Air Limbah Domestik bahwa periode penyedotan tangki septik harus dilakukan 3-5 tahun sekali. Hanya $36 \%$ masyarakat yang secara rutin melakukan pengurasan atau penyedotan lumpur tinja di tangki septik (Lihat Gambar 4). Hal ini dapat diartikan bahwa hanya 36\% masyarakat yang memiliki pengolahan setempat berupa tangki septik sesuai dengan SNI.

Selain itu, survey juga dilakukan untuk mengetahui volume pengolahan setempat yang dimiliki oleh masyarakat. Hasil survey tersebut menunjukkan bahwa terdapat $28 \%$ responden yang memiliki tangki septik dengan volume 4-5 $\mathrm{m}^{3}$ dan $21 \%$ dengan volume lebih dari $8 \mathrm{~m}^{3}$ (Lihat Gambar 5). Masyarakat cenderung membangun pengolahan setempat yang relatif besar dengan persepsi agar dapat digunakan dalam jangka waktu yang lama. Hal ini memperkuat analisis bahwa masyarakat masih belum mengetahui tentang standar pengolahan setempat dengan teknologi tangki septik. 




Gambar 3 Karkateristik Pengolahan Setempat di Kota Denpasar

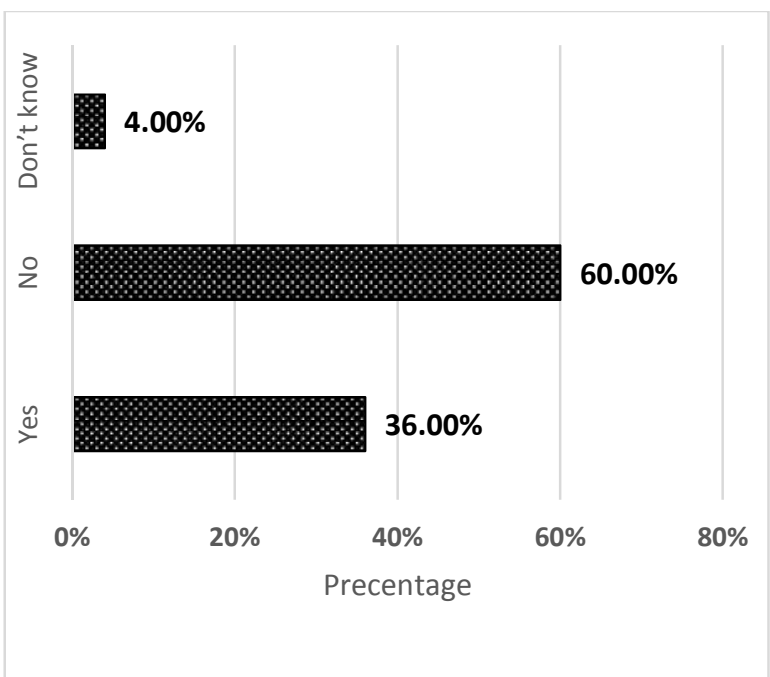

Gambar 4 Presentasi penyedotan tangki septikdalam 5 Tahun Terakhir

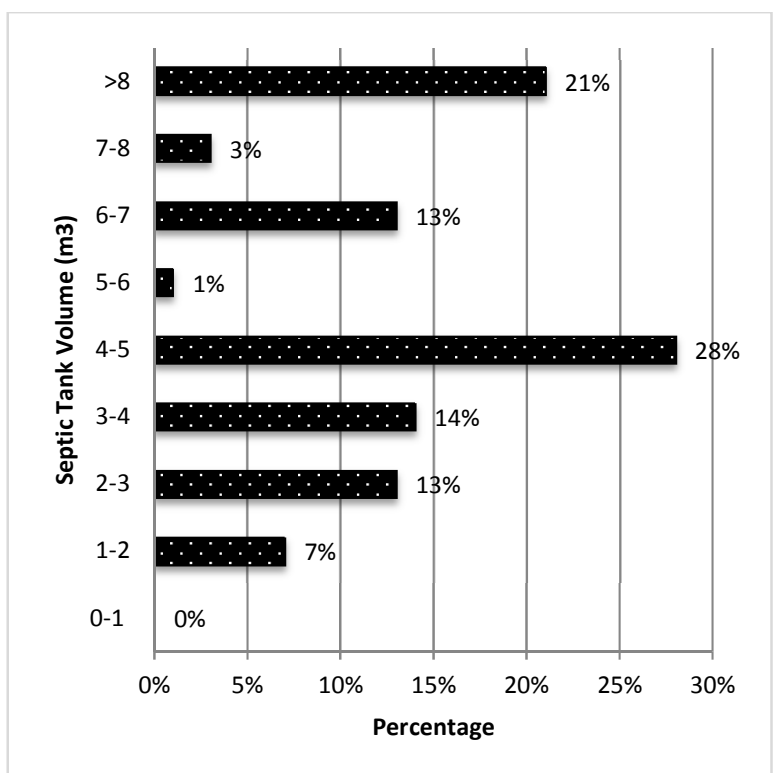

Gambar 5 Presentase Volume Tangki Septik di Kota Denpasar

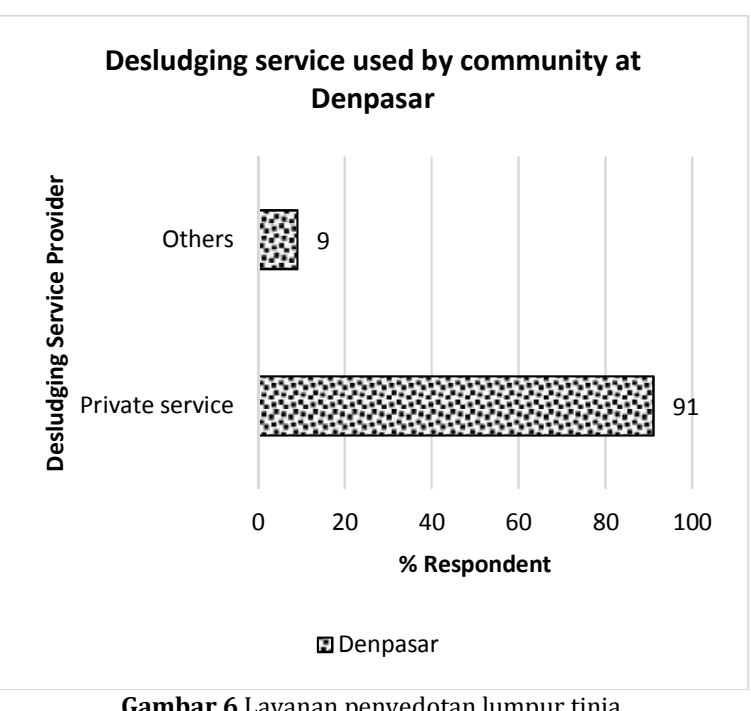

Gambar 6 Layanan penyedotan lumpur tinja

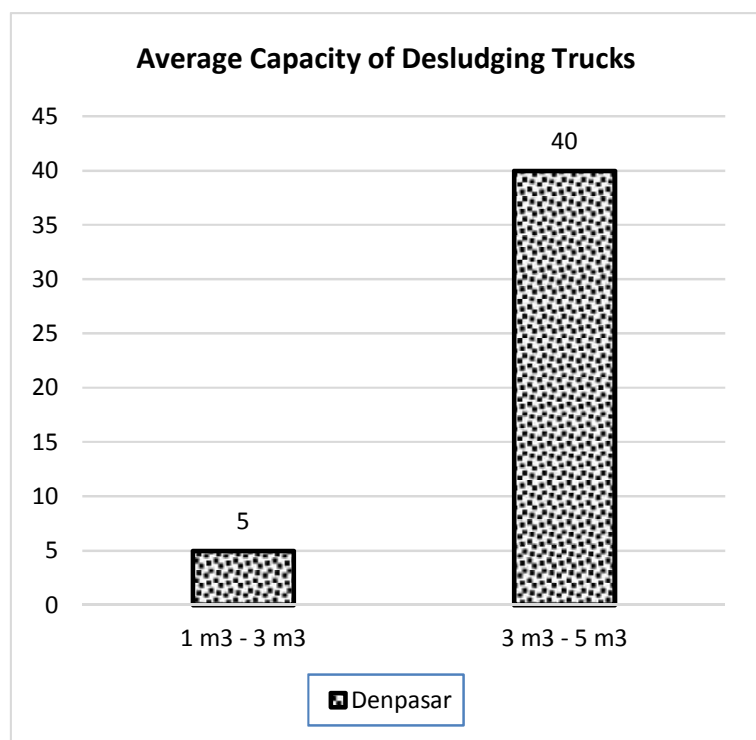

Gambar7 Kapasitas truk lumpur tinja

\section{Number of Houses that can be Desludge in A day}

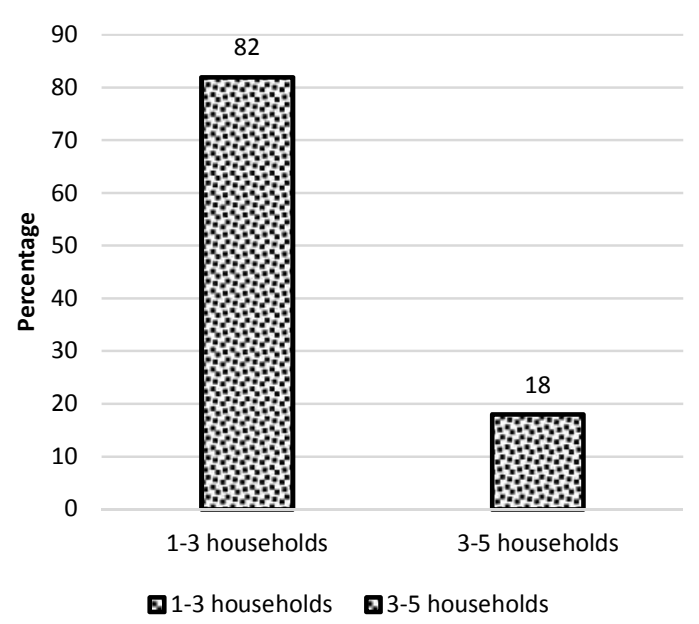

Gambar 8 Jumlah rumah yang dilayani per hari 


\subsection{Sub-sistem Pengangkutan Lumpur Tinja}

Hasil pengamatan dan wawancara terhadap pemangku kepentingan diketahui bahwa layanan penyedotan lumpur tinja di Kota Denpasar tidak hanya melayani pengolahan setempat yang berasal dari rumah tangga, namun juga bersumber dari restauran dan kawasan bisnis. Pelanggan pengurasan tangki septik di Kota Denpasar didominasi oleh perusahaan swasta. Terdapat $91 \%$ responden masyarakat yang memanfaatkan pihak swasta dalam melakukan pengurasan atau penyedotan lumpur tinja dan $9 \%$ responden menggunakan metode lain. Metode lain yang digunakan masyarakat dapat berupa pembuatan tangki pengolahan setempat yang baru atau menguras secara mandiri tanpa bantuan pihak swasta. Dalam hal ini, UPT PAL tidak melakukan pelayanan terhadap layanan penyedotan lumpur tinja.

Hingga Tahun 2018, Kota Denpasar memiliki 36 perusahaan swasta yang melayani jasa penyedotan lumpur tinjadengan total 77 armada truk sedot tinja. Kapasitas truk lumpur tinja di Kota Denpasar didominasi dengan ukuran 3 hingga $5 \mathrm{~m}^{3}$. Truk tangki dengan ukuran yang relatif besar ini digunakan untuk melayani pelanggan yang berasal dari restauran dan kawasan bisnis. Penggunaan truk tinja dengan ukuran lebih besar digunakanuntuk mengurangi jumlah ritasi menuju ke IPLT Suwung, Dengan kondisi saat ini, 82\% armada hanya mampu melayani 1-3 rumah tangga dan 18\% mampu melayani 3-5 rumah tangga (Lihat Gambar 8). Jumlah lokasi yang dapat dilakukan penyedotan ini relatif sedikit. Hasil pengamatan menunjukkan bahwa terdapat antrian yang relatif panjang saat melakukan pembuangan lumpur tinja di IPLT Suwung. Pembuangan lumpur tinja di IPLT Swung membutuhkan waktu sekitar 4-6 jam.

\subsection{Sub-sistem Pengolahan Lumpur}

Kota Denpasar telah memiliki IPLT yang berlokasi di Suwung dan dioperasikan oleh UPT PAL Provinsi Bali. IPLT Suwung memiliki teknologi yang relatif modern jika dibandingkan dengan IPLT lainnya di Indonesia. Lumpur tinja dari truk layanan lumpur tinja akan dialirkan masuk menuju ke IPLT. Terdapat beberapa unit pengolahan yang digunakan di IPLT Suwung, yakni mechanical separator, unit pengental atau thickener atau clarifier, unit anaerobic baffle reactor $(A B R)$, unit aerasi, stabilisasi dengan menggunakan kimia, dan belt filter press.

Hasil pengamatan menunjukkan bahwa IPLT Suwung belum dapat beroperasi secara maksimal. Terdapat beberapa permasalahan yang diduga menjadi penyebab terjadinya gangguan dalam pengoperasian IPLT Suwung, diantaranya lumpur tinja yang masuk kedalam IPLT didominasi dari restauran yang memiliki konsentrasi kandungan minyak dan lemak tinggi. Penumpukan lumpur yang didominasi oleh minyak dan lemak ini dapat dilihat dari tangki pengentalan atau clarifier yang tidak dapat memisahkan padatan dan air secara optimal. Hasil analisis laboratorium (lihat tabel 1) menunjukkan bahwa konsentrasi BOD dan COD di efluen IPLT
Suwung berturut-turut yakni $856-1.226 \mathrm{mg} / \mathrm{L}$ dan 2.787-5.474 mg/L. Hal ini menunjukkan performa IPLT Suwung tidak berjalan dengan baik. Pada tahun 2017-2018, pemerintah telah membangun unit pengolahan tambahan setelah unit aerasi berupa pengendapan kedua atau secondary clarifier untuk mengendapan padatan yang terbentuk selama proses aerasi. Namun, unit pengolahan ini belum beroperasi dikarenakan masih adanya permasalahan teknis lainnya.

\section{Tantangan dan Peluang \\ 4.1 Pengolahan Setempat}

Kota Denpasar masih dihadapi dengan cukup banyak tantangan dalam pengembangan SPALD-S. Walaupun Kota Denpasar sudah memiliki program DSDP untuk SPALD-T, namun tampaknya SPALD-S masih menjadi sistem yang realistis untuk digunakan, dioperasikan, dan dikembangkan di Kota Denpasar.

Hasil studi ini menunjukkan bahwa pengolahan setempat di Kota Denpasar masih didominasi dengan bangunan yang tidak kedap sesuai dengan SNI. Secara umum, masyarakat telah memiliki pemahaman yang baik tentang perlunya bangunan pengolahan setempat di setiap rumah namun masyarakat tidak mengetahui standar yang harus digunakan dalam membangun pengolahan setempat tersebut. Kondisi ini tentu berpotensi memberikan dampak terhadap pengoperasian SPALD-S.

Pemerintah telah memiliki standar untuk bangunan pengolahan setempat yakni SNI 2398:2017 tentang Tata Cara Perencanaan Tangki Septik dengan Pengolahan Lanjutan (Sumur Resapan, Bidang Resapan, Up Flow Filter, danKolam Sanita). Selain itu, pemerintah juga telah memiliki regulasi terkait air limbah domestik yakni Peraturan Pekerjaan Umum dan Menteri Perumahan No. 4 Tahun 2017 tentang Penyelenggaraan Sistem Pengelolaan Air Limbah Domestik (SPALD).Pemerintah perlu melakukan sosialisasi lebih intensif agar seluruh masyarakat serta pemangku kepentingan lainnya dapat mengetahui standar bangunan pengolahan setempat yang dapat digunakan untuk mengolah air limbah domestik dari permukiman maupun kawasan bisnis.

Sistem pengolahan setempat saat ini sudah cukup berkembang dengan tersedianya berbagai varian produk dengan metode dan material tertentu yang ditawarkan kepada masyarakat oleh produsen swasta. Produk ini tentu menjadi alternatif yang baik untuk dipilih oleh masyarakat karena praktis dan dibuat dari material yang kedap. Pemerintah perlu merespon perkembangan teknologi ini dengan memastikan produk tersebut sesuai dengan standar nasional dan memenuhi baku mutu lingkungan yang berlaku. Oleh karena itu, pemerintah perlu menyiapkan standar metode uji performa teknologi pengolahan setempat tersebut sebelum dilepas ke masyarakat. Mekanisme sertifikasi ini diharapkan dapat menjadi acuan dan jaminan bagi masyarakat dalam menentukan produk yang akan digunakan. 
Tabel 2. Hasil karakterisasi lumpur tinja di Kota Denpasar

\begin{tabular}{|c|c|}
\hline Isu/Permasalahan & Alternatif Solusi yang Dapat Diterapkan \\
\hline $\begin{array}{l}\text { Masyarakat tidak memiliki tangki septik } \\
\text { sesuai standar }\end{array}$ & $\begin{array}{l}\text { Diperlukan sosialisasi yang terstruktur untuk memperbaiki sanitasi } \\
\text { masyarakat untuk memenuhi standar yang ditetapkan } \\
\text { - Bantuan dari pemeritah masyarakat berpendapatan rendah untuk } \\
\text { membangun tangki septik yang. }\end{array}$ \\
\hline $\begin{array}{l}\text { Penyedot tangki septik tidak dilakukan } \\
\text { secara regular, hanya berdasarkan } \\
\text { permintaan dari pelanggan. }\end{array}$ & $\begin{array}{l}\text { - Penerapan LLTT untuk seluruh area pelayanan IPLT Suwung } \\
\text { - Denpasar harus mempunyai database yang terintegrasi dengan Sistem } \\
\text { Informasi Geografis (SIG) untuk membantu operator dalam pengelolaan } \\
\text { penyedotan lumpur tinja. }\end{array}$ \\
\hline $\begin{array}{l}\text { Tantangan untuk membuat tangki septik di } \\
\text { area yang padat penduduk }\end{array}$ & $\begin{array}{l}\text { - Masyarakat dapat membangun tangki septik atau IPAL komunal, sehingga } \\
\text { satu pengolahan ini dapat melayani banyak rumah tangga tanpa adanya } \\
\text { zonasi tertentu. }\end{array}$ \\
\hline $\begin{array}{l}\text { Masyarakat tidak mengetahui terkait sistem } \\
\text { LLTT }\end{array}$ & $\begin{array}{l}\text { - Dibutuhkan promosi mengenai program LLTT secara intensif ke seluruh } \\
\text { masyarakat } \\
\text { Kota Denpasr perlu melakukan kajian lebih mendalam untuk } \\
\text { mengintegrasikan retribusi air limbah dengan air bersih. }\end{array}$ \\
\hline $\begin{array}{l}\text { Operator penyedotan mengabaikan faktor } \\
\text { keselamatan, seperti tidak menggunakan } \\
\text { Alat Pelindung Diri (APD) pada saat } \\
\text { penyedotan }\end{array}$ & $\begin{array}{l}\text { - Dibutuhkan standar operasional pekerjaan bagi operator penyedotan lumpr } \\
\text { tinja. }\end{array}$ \\
\hline $\begin{array}{l}\text { Truk penyedot tinja serta alat pendukung } \\
\text { penyedotan seperti selang penyedotan tidak } \\
\text { dalam kondisi yang baik. }\end{array}$ & - Dibuatkan standar spesifikasi truk penyedot tinja. \\
\hline IPLT tidak beroperasi dengan efektif & $\begin{array}{l}\text { - Perlunya pengawasan untuk mengontrol lumpur tinja yang masuk kedalam } \\
\text { IPLT. Hal ini untuk memastikan karakteristik yang masuk sesuai dengan } \\
\text { kemampuan IPLT. } \\
\text { - Pengoperasian dan perawatan IPLT sesuai dengan SOP }\end{array}$ \\
\hline
\end{tabular}

\subsection{Pengangkutan Lumpur Tinja}

Mekanisme layanan penyedotan dan pengakutan lumpur tinja di Kota Denpasar masih menggunakan pendekatanon call services atau berdasarkan panggilan dari pelanggan. Pelanggan cenderung akan melakukan panggilan jika mendapati permasalahan dalam sistem pengolahan setempat. Pendekatan konvensional ini dinilai tidak cukup efektif dalam SPALD-S karena menimbulkan ketidakpastian volume lumpur tinja yang akan masukke IPLT. Ketidakpastian akan berdampak langsung pada tingginya fluktuasi lumpur tinja, sehingga akan mempengaruhi proses pengolahan di IPLT. Dalam konteks perencanaan, pendekatan on call services menjadi cukup sulit dalam penentuan kapasitas IPLT karena berpotensi tidak sesuai ketika dalam tahap operasi. Oleh karena itu, diperlukan metode alternatif lain yang lebih efektif dan efisien untuk mengoperasikan SPALD-S. khususnya Sub-sistem Pengangkutan.

Pemerintah Indonesia perlu untuk terus mengembangkan dan mensosialisasikan salah satu metode yang sudah dikeluarkan oleh kementerian terkait yakni metode Layanan Lumpu Tinja Terjadwal(LLTT). Secara umum, konsep LLTT dilakukan dengan menentukan zona layanan.Berdasarkan Peraturan Kementerian Pekerjaan Umum dan Perumahan No. 4 Tahun 2017, setiap zona ini akan menerapkan LLTT sesuai dengan periode penyedotan lumpur tinja (3-5
tahun).Program LLTT diharapkan dapat memberikan kontribusi yang signifikan dalam meningkatkan kinerja pengelolaanlumpur tinjapada setiap area layanan.

Untuk dapat menjalankan program tersebut, Kota Denpasar dinilai perlu juga untuk memiliki database tentang sanitasi terutama terkait infrastruktur SPALD-S. Database dapat dikembangkan dengan memanfaatkan teknologi Sistem Informasi Geografis (SIG) sehingga dapat lebih informatif dengan memasukan informasi-informasi terkait dan mudah diakses.Sistem ini dapat membantu operator untuk mengelola kegiatan penyedotan lumpur tinjasesuai pendekatan LLTT secara teratur. Tantangan dan solusi yang dapat diterapkan dalam pengelolaan lumpur tinja dapat dilihat pada Tabel 2 .

\subsection{Pengolahan Lumpur Tinja}

Kota Denpasar telah memiliki modern tetapi belum beroperasi dengan efektif dan efisien. Salah satu penyebab tidak efektifnya IPLT Suwung yakni lumpur tinja yang masuk dalam IPLT memiliki karakteristik berbeda yang bersumber dari restauran dan kawasan bisnis.Hasil analisis laboratorium menunjukkan performa sistem pengolahan yang tidak efektif dalam mendegradasi semua paramater yang diuji.

UPT PAL sebagai pengelola perlu melakukan edukasi kepada para pelanggan layanan pengelolaan 
lumpur tinja agar melakukan pengolahan awal untuk menyisihkan minyak dan lemak. Hal ini dilakukan agar beban pengolahan di IPLT Suwung dapat berkurang. Pengelola perlu menerapkan kriteria lumpur tinja yang dapat diterima dan diolah sesuai dengan spesifikasi disain IPLT Suwung.

\section{Kesimpulan}

Pengelolaan SPALD-S di Kota Denpasar masih dihadapkan dengan cukup banyak tantangan, dari Sub-sistem Pengolahan Setempat, Sub-sistem Pengangkutan, hingga Sub-sistem Pengolahan Lumpur.Masalah utama yang perlu menjadi perhatian seluruh pemangku kepentingan adalah kondisi pengolahan setempat masyarakat Kota Denpasar yang masih didominasi dengan teknologi pengolahan yang tidak sesuai dengan standar. Selain itu, metode layanan penyedotan dan pengangkutan lumpur tinja yang dijalankan oleh pihak swasta perlu dilakukan pengawasan agar lumpur tinja yang masuk sesuai dengan kemampuan IPLT. Metode LLTT perlu dipertimbangkan untuk diterapkan di masa depan dengan memanfaatkan SIG. Hal ini akan mempermudah pengawasan dan pengolahan lumpur tinja di IPLT.

Melihat kondisi saat ini, perbaikan-perbaikan teknis maupun non teknis perlu dilakukan dengan melibatkan semua pemangku kepentingan sehingga SPALD-S dapat berjalan dengan baik dan berkelanjutan. Kunci sukses penyelenggaraan SPALDS yang berkelanjutan dan jangka panjang adalah sinergi antara seluruh pemangku kepentingan diantaranya pemerinta daerah, pemerintah pusat, sektor swasta, masyarakat, dan komunitas lokal.

\section{Ucapan Terima Kasih}

Penulis mengucapkan terima kasih kepada Kementerian Lingkungan Jepang atas pendanaan yang diberikan dalam kegiatan yang berjudul "Integrated Approach for Dissemination of Decentralized Domestic Wastewater Treatment System in Southeast Asia" (11603).

\section{DAFTAR PUSTAKA}

Badan Pusat Statistik (BPS) diakses dari http://www.bps.go.id/, diakses padatanggal 2 Oktober 2018.

Badan Pusat Statistik Kota Denpasar. 2017. Kota Denpasar dalam Angka 2017. Denpasar: BPS

Heinss U., Larmie S.A., Strauss, M. 1998 Solids Separation and Pond Systems for the Treatment of Faecal Sludges in the Tropics. EAWAG/SANDEC. SANDEC Report No.5/98 Second Edition.

Henze, M., Comeau, Y. (2008). Wastewater characterization. In: Biological wastewater treatment: principles,modelling and design. Henze, $M$, van Loosdrecht, M.C.M., Ekama, G.A., Brdjanovic, D. eds. ISBN:9781843391883. IWA Publishing. London, UK

Indiyani, A., Mardikanto, A., Listyasari, M. (2017). Towards Nationwide Roll Out of Fecal Sludge Management in Indonesia. Proceedings of the 4th International
Faecal Sludge Management Conference. Available on:

http://www.fsm4.susana.org/downloads/conferen ce-materials

JMP (2017). JMP Global Database - WHO/UNICEF. Available on: https://washdata.org/

Lossing, P. Champagne, J. McLellan, Examinationof sludge accumulation rates and sludge characteris-tics for a decentralized community wastewater treat-ment systems with individual primary clarifier tankslocated in Wardsville (Ontario, Canada), Water Sci.Technol. 62 (12) (2010) 2944-2952.

Metcalf \& Eddy, Inc. (2014). Wastewater engineering : treatment and reuse. Boston :McGraw-Hill,

SNI: 2398-2017 - Tata Cara Perencanaan Tangki Septik dengan Sistem Resapan. Badan Standarisasi Nasional.

SNV (2017). Wastewater management in urban areas in Indonesia: SNV Indonesia's key finding and recommendations. Published by SNV. Available on: http://www.snv.org/update/wastewatermanagement-urban-areas-indonesia-snvindonesias-key-finding-and-recommendations

Soesanto, Sri Soewasti. 2000 Tangki Septik dan Masalahnya (Septic Tank and the Problem). Media Litbang Kesehatan, Vol. 10 No.1

STBM SMS-Based Monitoring Data in Indonesia, Ministry of Health, Available online:http://stbmindonesia.org/monev/ (accessed on 20 March 2018).

United States Environmental Protection Agency. 1984 Handbook: Septage Treatment and Disposal. EPA Municipal Environmental Research Laboratory. Cincinnati, Ohio. EPA-625/6-84-009.

United States Environmental Protection Agency. 1994 Guide to Septage Treatment and Disposal. EPA Office of Research and Development. Washington, D.C. EPA/625/R-94/002.

United States Environmental Protection Agency. 2002 USEPA Onsite Wastewater Treatment Systems Manual. Officeof Water.

WHO/UNICEF Joint Monitoring Programme. 2017 Progress on Sanitation and Drinking Water 2017 Update and SDG Baseline; World Health Organization: Geneva, Switzerland.

World Bank (2008) Economic Impacts of Sanitation in Indonesia - A five-country study conducted in Cambodia, Indonesia, Lao PDR, the Philippines, and Vietnam under the Economics of Sanitation Initiative (ESI) Water and Sanitation Program East Asia and the Pacific (WSP-EAP). World Bank. Available on: http://www.wsp.org/sites/wsp.org/files/publicati ons/esi_indonesia.pdf

World Bank. 2013 Urban Sanitation Review: Indonesia Country Study, Washington, DC. (C) World Bank. https://openknowledge.worldbank.org/handle/10 986/17614 License: CC BY 3.0 IGO.

World Bank (2016) Indonesia's Urban Story. World Bank. Available on: http://www.worldbank.org/en/news/feature/201 6/06/14/indonesia-urban-story

World Bank (2017). Meeting Indonesia's Urban Sanitation Needs. Published by The World Bank. Available on: http://www.worldbank.org/en/news/feature/201 7/03/21/meeting-indonesia-urban-sanitationneeds 